Article

\title{
Simulating the Barriers of Transaction Costs to Public Rental Housing Exits: The Case of Wuhan, China
}

\author{
Jintao Li ${ }^{1}$, Xin Ning ${ }^{2}$, Jun Sun ${ }^{3, *}$ and Xiaoqian Xiong ${ }^{3}$ \\ 1 School of Civil Engineering, Architecture and Environment, Hubei University of Technology, No.28, \\ Nanli Road, Hong-shan District, Wuchang, Wuhan 430068, China; jintaohbut@hbut.edu.cn \\ 2 School of Investment \& Construction Management, Dongbei University of Finance \& Economics, \\ Dalian 116025, China; ningxin@dufe.edu.cn \\ 3 School of Civil Engineering and Mechanics, Huazhong University of Science and Technology, \\ Luoyu Road 1037, Hong-shan District, Wuchang, Wuhan 430074, China; xiongxq@hust.edu.cn \\ * Correspondence: sunjunym@hust.edu.cn; Tel.: +86-027-8755-6945
}

Received: 7 April 2018; Accepted: 11 May 2018; Published: 14 May 2018

\begin{abstract}
The purpose of this paper is to explore and simulate the barriers of transaction costs to public rental housing (PRH) exits in China. The two-period model of household consumption utility, with the constraints of transaction costs, is employed to conduct our analysis. The overall results show that if transaction costs go beyond the tenants' ability to afford them, the tenants will continue to live in the current PRH units, resulting in an obstruction of PRH exits. When the rent ratio in the two periods is higher than 1 and continues to rise, a higher proportion of transaction costs for household consumption contributes to a greater impeding effect, so the barriers' effect with regards to concurrent changes in rent and income is similar to that of changes only in rent. We observe a close relationship between the acceptable maximum transaction costs and the variety of housing rents. If the tenants cannot afford the maximum transaction cost or housing rent in the private market, they will stop searching for a more advantageous housing and will prefer living in the current PRH units. Moreover, the proportion of maximum acceptable transaction costs does not vary with the changes in the expected household income; income growth only increases the absolute value of transaction costs, not the relative one. Therefore, the government should not only provide housing search services to help tenants leave the public rental sector, but should also adjust the supply of affordable housing for households with housing stress.
\end{abstract}

Keywords: PRH exits; transaction costs; barriers; two-period model; Wuhan

\section{Introduction}

In China, public rental housing (PRH) is considered to be a more effective and realistic solution for solving the housing stress of low-income families, and is also an important part in building the nation's social safety net [1]. The Chinese government has recently launched an ambitious plan for PRH in the 12th Five-Year Plan (2011-2015). According to the Ministry of Housing and Urban-Rural Development (MOHURD), 16.6 million units of PRH were completed by the end of 2014, helping a large number of families that are struggling with housing problems to achieve their dream of having a home of their own [2]. Currently, the PRH has become an important part of the national basic service system. However, various issues related to the PRH allocation have been consistently reported by the media, such as provision of false information in a PRH application, subletting the unit, and unlawful assignment [3]. Moreover, some tenants refused to exit from PRH units when their lease ran out. A report published by the National Audit Office of China (NAOC) stated that a large number of tenants, who were capable of working and bouncing out of the low-income group and were no 
longer qualified for the PRH, continued to enjoy the units and rental subsidies [4]. The limitation that unqualified tenants do not depart from public units has brought a series of challenges to the fair allocation of PRH. The dilemma faced by the so-called emerging "exit difficulty" in the public housing sector has attracted a great deal of attention from the media, government, and scholars [5]. Although the MOHRUD has announced that China would stop construction of new PRH units by the end of 2015, the management of the PRH exit in a fair and efficient way is still one of the most important elements to solve in order to achieve the final objective of ensuring "adequate housing for everyone" [6]. From the urban social geography standpoint, the PHR exit is a kind of internal residential mobility in daily life. While residential mobility is the outcome of the housing market search [7], a crucial premise is that the tenants can access a suitable house in the private market. If the search for a new house is too frustrating, the tenants may choose to stay in the original PRH units. Thus, it is important to identify existing barriers in housing search behavior and the decision-taking process-and ultimately, the final outcome.

It has been argued that expectations about future change are important factors in understanding residential mobility [8]. A substantial body of literature examined the relationship between residential mobility and the housing search [9]. In China, academic discussions of the determinants of "exit difficulty" have focused mainly on qualitative analyses and solutions to those analyses [10]. For example, few studies have sought to explore the determinants of tenants' intention to exit PRH units [11,12]. Only a few studies have explored information search and transaction costs in the housing market; thus, little research has investigated the barriers of those transaction costs to the PRH exits. In contrast to prior qualitative studies showing that some barriers, such as dishonest practices, ambiguous laws and regulations, or a lack of rewards and punishments, are related to the PRH exits, our study aims to highlight the barriers of transaction costs to PRH exits by simulating the tenants' housing adjustment process. We model the tenants' housing adjustment process under a housing search and transaction costs. Then, the economic costs of the tenants' constraints are computed. These costs may be interpreted as the barriers to PRH exits.

The paper is structured as follows. The second section reviews the existing literature related to the housing search with relation to residential mobility and the main determinants of public housing exits. The third section discusses the methodological design employed, namely the two-period model with several constraints to simulate the barriers of transaction costs to the PRH exits. Section Four includes the description of the data and the simulation methods employed. Section Five discusses the simulation results. Last, we summarize the main results and suggest some future research avenues with different policy implications.

\section{Literature Review}

Since the pioneering work of Rossi [13], residential mobility decision making has continuously attracted scholars' attention in regards to numerous disciplines. Consequently, sociologists, economists, and psychologists have attempted to explore residential mobility behavior [14]. More specifically, residential mobility refers to intra-urban moves that are intricately related to the housing market and urban changes. Much of the existing literature focuses mainly on residential mobility in the housing market context.

Residential mobility, including the housing search, transaction, and moving involves a complex and lengthy process with continuous decision making [15]. A great number of longitudinal and cross-sectional studies have shown a discrepancy between positive attitudes towards moving and actual mobility behavior. Those who intend to move have a different probability of realizing their intention to move, as some households cannot find a suitable or affordable dwelling that meets their preferences [16,17]. However, backed by sufficient financial resources, information, and social network, the desire to move can be actually achieved, and is perceived as generating positive outcomes [18]. Therefore, residential mobility is guaranteed, not only by the individual financial resources and restrictions, but also by the opportunities and constraints in the housing market [7]. 
However, some studies have suggested that demographic factors, such as education, employment, health, and even mental health are not considered as predictors for a family's duration of stay in a specific place [19]. In market economies, residential mobility is the outcome of a housing search, though the actual materialization of intentions to move depends on the intensity of the housing search and the availability and accessibility of residential opportunities in the market. A variety of aspects related to the search strategy, as well as the intensity of searching efforts, search space, and types of information sources affect the search outcomes [15]. There are two types of problems influencing searching behavior, including the increasing costs of searching or gathering information and the limited choices of housing units or locations available to households. Among the factors that may be conceptualized as problems, and which are raising important search costs, are the following: lack of knowledge about where to search, lack of transportation access for searching, and lack of child care support while searching. A myriad of structural barriers, such as public transportation access, affordable housing availability, and poor quality housing units, made it difficult for households to make permanent exits from current neighborhoods [20]. In addition, in the private market, the discrimination by landlords also plays a significant role in household mobility [21]. Furthermore, housing choice factors, including rent, dwelling attributes, and travel time to work or school, tend to be highly correlated with the households' decision to move [22]. It is clear that the above-mentioned factors are strongly associated with the costs related to the mobility process. Transaction costs are important factors influencing the final outcome of the decision to move $[23,24]$. If the transaction costs are higher than the constraints of household consumption, households will choose to stay in the original housing instead of moving, highlighting the importance played by transaction costs and their role as barriers in the housing consumption adjustment [25]. Lower transaction costs, a more responsive housing supply, lower rent controls, and tenant protection can promote residential mobility [26].

China does not have a long history of social and political concerns about rental security housing [27]. Thus, a relatively small strand of literature related to public housing exits has been analyzing this issue [11]. Consequently, most of the existing literature focused on the qualitative analysis of unsmooth exits from social security housing [5]. Although some scholars explore the information search and transaction costs in the housing market [28-30], a small family of papers is actually investigating the connection between PRH exits and residential mobility. However, some gaps from prior research emerge, so there is a lack of clarity in relation to the barriers of transaction costs to the PRH exits. Consequently, our main purpose is to fill in the gap in the literature. In addition, in the private market, low-income families face higher constraints on housing choices and preferences compared to more advantaged families [31]. For example, if a family cannot afford the minimum required down payment on a home that is worth owning, then that family's most viable alternative option is to rent a home until it can afford a sufficient down payment [32]. Thus, we assume that the tenants will choose to rent a home from the private housing market after moving out of the PRH units.

\section{Methodological Approach}

Residential mobility decision-making is a complex process, and it can be regarded as a function of utility maximization and rational choices on the basis of cost-benefit calculations about a households' needs and preferences [33,34]. Therefore, the tenants will more likely exit from the PRH units and enter the private rental housing market if the mobility would make their housing consumption better. As expected, finding a suitable and accessible house may involve transaction costs, such as search costs, negotiation costs, transaction taxes, and moving costs. In addition, housing mobility, particularly involving a new neighborhood, is a classic example of a multidimensional and inter-temporal decision [35].

The key analytical framework with reference to the tenants' exit decision can be grounded on a two-period model of housing demand. The first period of housing demand refers to the housing consumption in the PRH units, while the second period represents the housing need in the private rental sector after moving out of the PRH units. This framework considers a simple inter-temporal 
utility maximization model, where special attention is given to PRH exits and the role of the transaction costs of housing mobility.

The tenant's household consumption utility in periods 1 and 2, a function of housing services, $h=\left(h_{1}, h_{2}\right)$, and non-housing goods and services, $c=\left(c_{1}, c_{2}\right)$, can be built by adopting the classic Cobb-Douglas production function, as shown in Equations (1)-(3).

$$
\begin{gathered}
U_{1}=h_{1}^{\alpha} c_{1}^{\beta}+\frac{1}{1+i} h_{2}^{\alpha} c_{2}^{\beta} \\
\text { s.t. } y_{1}=r_{1} h_{1}+c_{1}+s \\
y_{2}=r_{2} h_{2}+c_{2}-(1+i) s
\end{gathered}
$$

In Equation (1), we suppose the maximum consumption utility as being subject to tenant's income $y_{1}$ and $y_{2}$ in periods 1 and 2. Where $\alpha$ is the share of housing services to total household consumption, $\beta$ is the share of non-housing goods and services to total consumption, and $i$ is the discount rate. In the constraint equations, $r_{1}$ and $r_{2}$ represent the housing rents of the PRH unit and the private sector, respectively, and $s$ represents the household savings. In our model, tenants can perfectly foresee the income, the rents of housing, and the prices of other goods and services, and afterwards they decide on an optimal consumption plan for $c_{1}, c_{2}, h_{1}$, and $h_{2}$. The housing adjustment between periods 1 and 2 involves the decision about whether to move from the PRH unit to a private rental unit.

In the process of housing adjustment, however, the transaction costs are not zero. If the tenants want to access to the private rental market, their decisions to exit the PRH units is accompanied by transaction costs that involve both a lump sum (including search and moving costs) and proportional components, which are usually related to the total housing expenditure $r_{i} h_{i}$. For reasons of presentation, we consider only the lump sum component, and we denote this sum by $t$. The optimal household utility by considering transaction costs is shown in Equations (4)-(6).

$$
\begin{gathered}
U_{2}=h_{1}^{\alpha} c_{1}^{\beta}+\frac{1}{1+i} h_{2}^{\alpha} c_{2}^{\beta} \\
\text { s.t. } y_{1}=r_{1} h_{1}+c_{1}+s \\
y_{2}-t=r_{2} h_{2}+c_{2}-(1+i) s
\end{gathered}
$$

If the tenants do not intend to exit the PRH units when their household income increases, they do not need to adjust their housing consumption, though they can adjust the non-housing goods and services. At that time, the optimal household consumption utility considering the influence of transaction costs may be expressed as follows:

$$
\begin{gathered}
U_{3}=\bar{h}^{\alpha} c_{1}^{\beta}+\frac{1}{1+i} \bar{h}^{\alpha} c_{2}^{\beta} \\
\text { s.t. } y_{1}=r_{1} \bar{h}+c_{1}+s \\
y_{2}=r_{2} \bar{h}+c_{2}-(1+i) s
\end{gathered}
$$

where $\bar{h}$ refers to the constrained housing rent in each period, and $\bar{h}=h_{1}=h_{2}$.

When the tenants make the decision to exit the PRH units, the optimal consumption utility $u_{2}$ and $u_{3}$ will be simulated for comparison purposes. If $u_{2}$ is greater than $u_{3}$, the tenants will choose to bear the transaction costs and move out of the PRH units. On the contrary, if $u_{2}$ is smaller than $u_{3}$, the tenants will remain in the PRH units, due to the barriers regarding transaction costs. Figure 1 represents the tenants' exit decision and housing adjustment during two periods. 


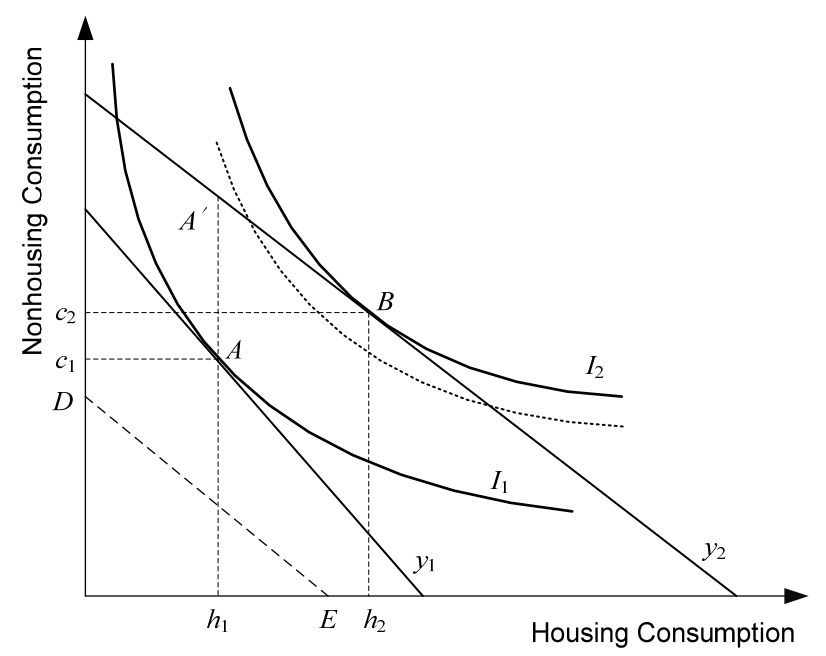

Figure 1. Two-period consumption optimization with transaction costs.

In period 1, the tenants live in the PRH units, where the optimal household consumption with income constraint $y_{1}$ is $A$, the tenants' housing consumption is $h_{1}$, and non-housing consumption is $c_{1}$. When the household income increases, the tenants will move out of the PRH units and search for a house on the private housing market in period 2. If the transaction costs $t$ are equal to zero, then optimal consumption will move from $A$ to $B$, representing an increase in the housing and non-housing consumption. With a positive $t$, the second period's indifference curve $I_{2}$ shifts inward, thus the tenants may choose to stay in the PRH units. If the transaction costs are high enough to offset the benefits of the income growth, the total utility in the two periods after relocation may be less than the total utility without moving. As such, the tenants may remain in the original housing consumption as in period 1 , and purchase more $c_{2}$ than is provided at $A$. By staying in the original PRH units, the tenants' consumption choice can move from $A$ to $A^{\prime}$. In addition, if the transaction costs are large enough, the budget constraint will shift to left, even as far as $D E$. As a result of a lower consumption utility in period 2 compared to period 1, the tenants will not manifest the intention to exit the PRH units. Therefore, transaction costs can be seen among the most important barriers in the PRH exits.

\section{Data Description and Simulation Methods}

The two-period model of household utility requires considerable data for the simulation of the transaction costs barriers to the PRH exit. We assume that household income can be used for housing and non-housing consumption, but also for savings, so we set $\alpha+\beta<1$. In this simulation, we assume $\alpha+\beta=0.9$. The typical method of measuring housing affordability defines a household to be in housing stress if household spends more than 30 per cent of income on housing costs [36]. In this case, the share of housing services to total household expenditures $\alpha$ is set at 0.27 , while the share of non-housing goods and services $\beta$ is 0.63 . We define a five-year discount rate of $8 \%$ in response to the one-year bank deposit rate. Although the discount rate may vary slightly over time, for ease of calculation, the simulations will set the two rates to be equal in periods 1 and 2 . The current popular tenancy in the PRH unit in Wuhan is five years, so we set the simulation length at five years in both periods 1 and 2; consequently, two periods cover ten years. The tenants can plan their housing and non-housing consumption at the beginning of period 1 (the first year) and period 2 (the sixth year), or they can adjust savings or bank loans to suit the household consumption demand. In 2016, the income eligibility threshold for PRH candidates in Wuhan covered the households who had a monthly per capita income of 3000 yuan or below. That is, tenants with an annual income of 36,000 yuan and above are no longer eligible for the PRH program. According to the publicly available data from the Wuhan Housing Security and Management Bureau, the vast majority of tenants with minimal savings have a monthly income of around 3000 yuan, and the most common applicants are the ones with a household 
of two people. We assume that there is no difference in initial endowments between tenants. Thus, tenants' annual household income is set at 75,000 yuan. The total household income is 375,000 yuan in periods 1 and 2, respectively.

We have followed three steps in the simulation process. First, according to the household utility $u_{1}$, we have found the optional optimal household consumption expenditure without considering transaction costs. Second, we have calculated the maximum household utility with barriers of transaction costs through total utility $u_{3}$. Finally, the maximum value of transaction costs $t$ has been obtained by substituting the maximum total utility $u_{3}$ into utility $u_{2}\left(u_{2}=u_{3}\right)$. Here $t$ is the largest transaction cost that the tenants can afford in the process of housing adjustment. When the transaction costs are higher than this threshold value, the total household utility after housing adjustment is less than the total utility of staying in the PRH units, thus the tenants will prefer not to move out of the public rental units. Consequently, the PRH tenants will still remain in the PRH units, because of the barriers related to transaction costs.

\section{Simulation Barriers of Transaction Costs to the Public Rental Housing Exit}

\subsection{Barriers of Transaction Costs with Changes in Housing Rent}

This section measures the barriers of transaction costs through simulations with changes in the housing rent. The first calculation begins by maximizing the household utility based on the utility $u_{1}$, without the constraints of transaction costs. In this process, the results of maximum utility $u_{1}$ are related to the changing rents in periods 1 and 2 , using the rent ratio $\left(r_{2} / r_{1}\right)$ to represent those changes. The current rent standards of the PRH units in Wuhan are approved by the housing security authority, who investigates the rents of the contiguous private housing. While the actual paid rents are less than the market rents, due to the rent subsidies, the rent ratios we set in our analysis vary from 0.7 to 1.8. According to the total utility $u_{1}$, we get the simulation results on the effects of rent changes in household consumption before and after the housing adjustment, without taking into account the transaction costs, as shown in Table 1. For example, when household income and the housing rent remain unchanged in periods 1 and $2, y_{1}=y_{2}=375,000$ yuan and $r_{2} / r_{1}=1.0$, the household consumption of housing services is 11.25 units, and the savings is zero. The optimal household consumption solution is not to adjust the housing while the transaction costs are at zero level. In our case, the transaction costs are not working for this optimal solution.

Table 1. The influences of changes in rent on household consumption without transaction costs.

\begin{tabular}{|c|c|c|c|c|c|c|}
\hline \multirow{2}{*}{$r_{2} / r_{1}$} & \multicolumn{2}{|c|}{ Period 1} & \multicolumn{2}{|c|}{ Period 2} & \multirow{2}{*}{$s$} & \multirow{2}{*}{$U_{1}$} \\
\hline & $h_{1}$ & $c_{1}$ & $h_{2}$ & $c_{2}$ & & \\
\hline 0.7 & 6.32 & 14.76 & 23.67 & 38.66 & 16.42 & 30.73 \\
\hline 0.8 & 8.05 & 18.78 & 18.38 & 34.31 & 10.67 & 29.99 \\
\hline 0.9 & 9.71 & 22.66 & 14.34 & 30.12 & 5.12 & 29.44 \\
\hline 1.0 & 11.25 & 26.25 & 11.25 & 26.25 & 0.00 & 29.01 \\
\hline 1.1 & 12.63 & 29.46 & 8.88 & 22.78 & -4.59 & 28.67 \\
\hline 1.2 & 13.84 & 32.28 & 7.05 & 19.73 & -8.62 & 28.41 \\
\hline 1.3 & 14.88 & 34.72 & 5.64 & 17.10 & -12.10 & 28.21 \\
\hline 1.4 & 15.78 & 36.81 & 4.54 & 14.84 & -15.09 & 28.04 \\
\hline 1.5 & 16.54 & 38.60 & 3.69 & 12.92 & -17.64 & 27.91 \\
\hline 1.6 & 17.19 & 40.11 & 3.02 & 11.28 & -19.81 & 27.80 \\
\hline 1.7 & 17.75 & 41.41 & 2.49 & 9.88 & -21.65 & 27.71 \\
\hline 1.8 & 18.22 & 42.51 & 2.07 & 8.69 & -23.22 & 27.64 \\
\hline
\end{tabular}

In the second calculation we have maximized the total utility $u_{3}$, and substituted it into the function of total utility $u_{2}$, where $u_{2}=u_{3}$, so that the maximum transaction costs tenants could afford 
are attained. In our case, the consumption decision of total utility $u_{2}$ is the optimal choice with transaction costs. The calculation results are presented in Table 2.

Table 2. The influences of changes in rent on household consumption without transaction costs.

\begin{tabular}{cccccccccc}
\hline \multirow{2}{*}{$\boldsymbol{r}_{\mathbf{2}} / \boldsymbol{r}_{\mathbf{1}}$} & \multirow{2}{*}{$\boldsymbol{U}_{\mathbf{3}}$} & $\bar{h}$ & \multicolumn{2}{c}{ Period 1 } & \multicolumn{2}{c}{ Period 2 } & & \multirow{2}{*}{$\boldsymbol{s}$} & \multirow{2}{*}{$\mathbf{1}(\mathbf{\%})$} \\
\hline 0.7 & 30.25 & 13.15 & 6.22 & 14.51 & 23.27 & 38.00 & 16.78 & 1.33 & 8.05 \\
0.8 & 29.81 & 12.45 & 8.00 & 18.66 & 18.26 & 34.08 & 10.85 & 0.53 & 3.62 \\
0.9 & 29.40 & 11.82 & 9.70 & 22.63 & 14.32 & 30.08 & 5.17 & 0.12 & 0.94 \\
1.0 & 29.01 & 11.25 & 11.25 & 26.25 & 11.25 & 26.25 & 0.00 & 0.00 & 0.00 \\
1.1 & 28.64 & 10.73 & 12.61 & 29.43 & 8.86 & 22.75 & -4.54 & 0.10 & 0.99 \\
1.2 & 28.30 & 10.26 & 13.77 & 32.14 & 7.02 & 19.64 & -8.41 & 0.35 & 4.18 \\
1.3 & 27.97 & 9.83 & 14.74 & 34.40 & 5.58 & 16.94 & -11.64 & 0.72 & 9.88 \\
1.4 & 27.66 & 9.44 & 15.54 & 36.26 & 4.47 & 14.62 & -14.30 & 1.17 & 18.47 \\
1.5 & 27.37 & 9.07 & 16.18 & 37.76 & 3.61 & 12.64 & -16.45 & 1.68 & 30.37 \\
1.6 & 27.09 & 8.73 & 16.52 & 38.97 & 2.93 & 10.96 & -18.17 & 2.22 & 46.03 \\
1.7 & 26.82 & 8.42 & 17.10 & 39.92 & 2.40 & 9.53 & -19.53 & 2.79 & 65.87 \\
1.8 & 26.57 & 8.13 & 17.43 & 40.67 & 1.98 & 8.32 & -20.60 & 3.36 & 90.27 \\
\hline 1
\end{tabular}

${ }^{1} p$ represents the percentage of maximum transaction costs to housing consumption.

Table 2 reports the results regarding the influence of transaction costs on the consumption of housing services under changes in the housing rent. For example, when the rent ratio $r_{2} / r_{1}=0.7$, tenants are expecting the private rent to be lower than the current level of the PRH unit after moving out of the public housing sector. The optimal consumption decision for a tenant is 6.32 units of housing services in period 1 and 23.67 units in period 2, with 16.42 units of savings. Given the lower rent in the private sector than for the PRH unit, the tenants increase their housing and non-housing consumption to 23.27 and 38 units in period 2, and achieve the maximum total household utility within two periods. If the households choose not to exit the PRH units, they enjoy the same consumption of housing services, namely 13.15 units, in both periods 1 and 2. If the tenants choose to leave the PRH units, that is, adjust their housing demand at the end of period 1, the maximum transaction costs they can afford are 1.33 units, representing $8.05 \%$ of housing services consumption. This result implies that tenants will adjust the housing demand at the beginning of period 2 , when the total utility $u_{2}$ is greater than $u_{3}$, with transaction costs constraints under 1.33 units. On the contrary, if the transaction costs exceed 1.33 units, the total household utility without housing adjustment will become an optimal alternative. Then the tenants have the choice to stay in the PRH units or delay their departure.

When $r_{2} / r_{1}=1.7$, the housing rent in the private sector is expected to be higher than in the public sector, thus the tenants will increase housing consumption to 17.75 units in period 1, and decrease it to 2.49 units in period 2. At this time, the maximum transaction costs are 2.79 units, representing $65.18 \%$ of housing consumption. When the transaction costs are less than 2.79 units, total utility $u_{2}$ is greater than $u_{3}$, thus tenants choose to move out of the PRH units, or otherwise they still stay in the original public units. In the latter case, the expected rent and transaction costs in period 2 are higher than those of period 1 , while $u_{2}$ is lower than $u_{3}$. According to prospect theory [37], the extra rent and transaction costs are considered as losses. In general, many households are loss averse with regard to decisions about housing mobility, and postpone or even cancel previously intended moves [35]. Engelhardt [38] also found that loss aversion leads to reduced mobility. Thus, the expected high rent and transaction costs are associated with the barriers to PRH exits.

Figure 2 shows the effect of rental changes on tenants' household consumption. With an increase in the rent ratio, the housing services consumption in period 1 and 2 shows an upward and downward trend, respectively, with a higher downward speed than the upward one. This implies that when the rent is expected to increase, the tenants will gradually increase housing services consumption in period 1 but reduce it in period 2 , in order to meet the maximum total household utility within the two periods. 
Figure 2 also reveals the changes in housing services consumption with transaction costs constraints. If the tenants' intention is not to exit the PRH units, they will adjust their housing services consumption, along with the changes in the rent ratio, to attain the optimal total utility, although the adjustment speed is significantly lower than that in periods 1 and 2 without the barriers of transaction costs.

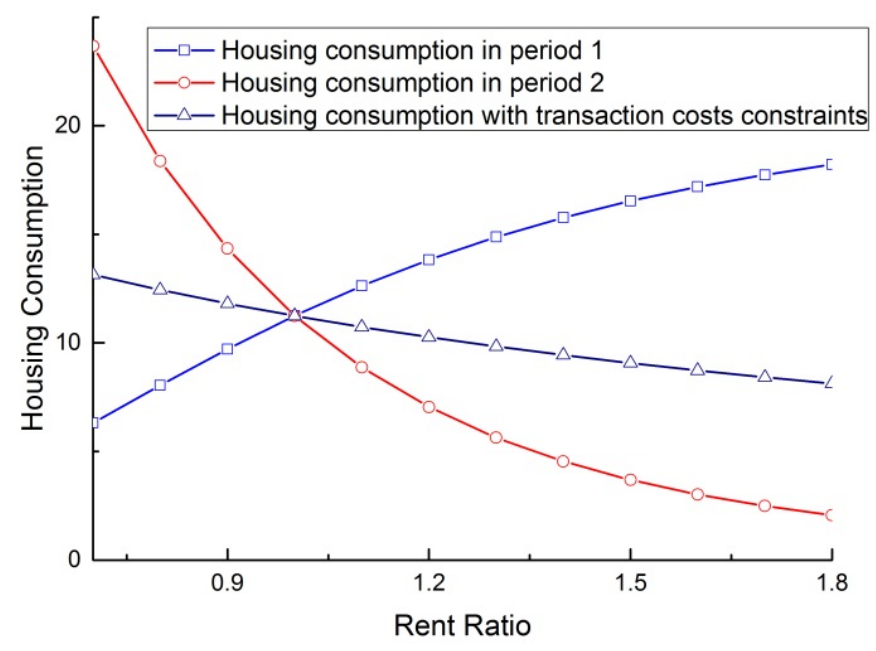

Figure 2. Influence of the rent ratio on housing consumption.

Figure 3 describes the fluctuations of the acceptable maximum transaction costs in relation to the rent ratio. We can see that the changes in the maximum transaction costs are attributed to the U-shaped curve. If the rent ratio within two periods is equal to 1 , tenants' acceptable maximum transaction costs are zero. When the rent ratio is less than 1 , the acceptable maximum transaction costs will gradually increase along with a decrease of the rent ratio. When the rent ratio is higher than 1 , we can observe a gradual increase in the rent ratio. The proportion of the acceptable maximum transaction costs to housing services consumption (Figure 3) can be represented as the barriers of transaction costs to housing adjustment. In this case, the higher transaction costs imply important barriers to housing adjustment. In addition, when the rent ratio is lower than 1, the barrier effects will gradually weaken with an increase in the rent ratio. However, the effects will further strengthen while the rent ratio becomes higher than 1 .

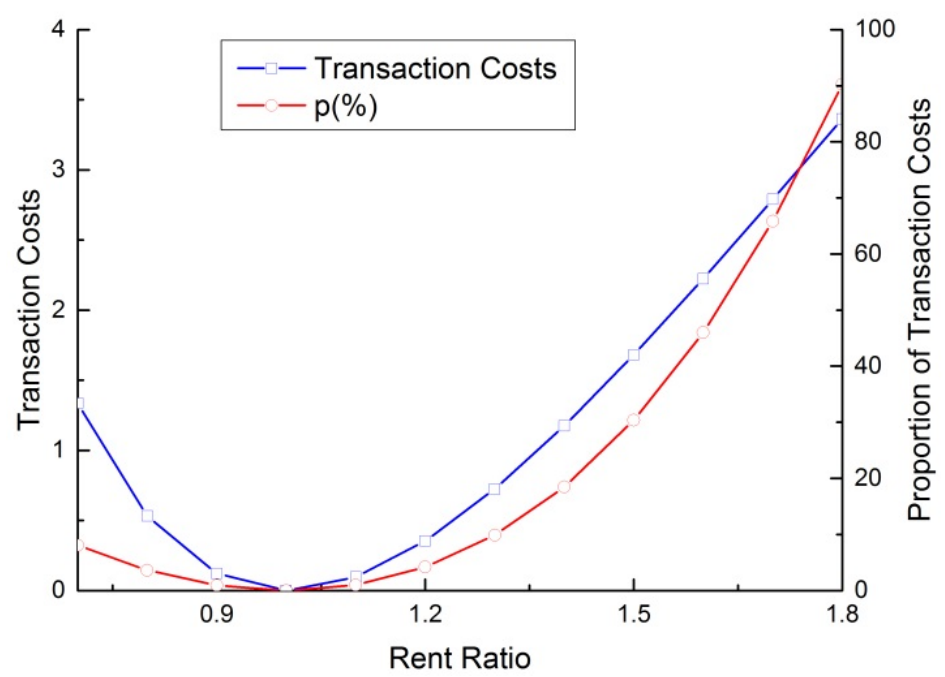

Figure 3. Transaction costs considering rental changes. 
According to the simulation results above, we can predict the exit decisions of tenants' who no longer enjoy PRH eligibility. From our point of view, the levels of generalized transaction costs vary widely among different countries. Some studies estimate the total transaction costs by calculating how much a household is willing to pay to move out of the current dwelling, if no change in the variables is observed. For example, Bartik et al. [39] estimated that the moving costs have a range between $10 \%$ and $20 \%$ of total income. For low-income renters in Pittsburgh households, the median out-of-pocket moving costs are $14 \%$ of the monthly income [40]. Additionally, Zhang et al. [29] estimated that the optimal transaction costs are $8 \%$ of the housing value. Generally, transaction costs of moving into owner housing are considerably higher than those of moving into renter housing [23]. We assume that the maximum transaction cost one can afford is $8 \%$ of housing services consumption, when tenant's annual household income is still 75,000 yuan. Afterwards, we calculate that the rent ratio, within the previously discussed constraints, belongs to the interval 0.701 to 1.267 . That is, when the rent ratio varies from 0.701 to 1.267 , and the transaction costs are less than $8 \%$ of housing services consumption, the tenants will adjust the housing demand and exit the PRH units. However, considering the fact that it is difficult for tenants to search for a suitable house, due to the high transaction costs that are far beyond tenants' affordability level, the tenants will tend to remain in the same place, namely in the PRH units (in other words, remain "locked" in the public rental sector).

\subsection{Barriers of Transaction Costs under Changes in Rent and Income}

We can also simulate the barriers of transaction costs, considering the changes in housing rent and income based on the two-period model of the total household utility. In this section, we assume the following: (i) tenants' annual household income in period 2 is not smaller than the income in period 1; (ii) the range of income ratio is between 1 and 1.25; (iii) the rent ratio is still in the range of 0.7 to 1.8. In Table 3, we note some of the simulation results of the barriers of transaction costs to housing adjustment.

Table 3. The influences of changes in rent and income on household consumption, with transaction costs constrains.

\begin{tabular}{|c|c|c|c|c|c|c|c|c|}
\hline \multirow{2}{*}{$r_{2} / r_{1}$} & \multirow{2}{*}{$y_{2} / y_{1}$} & \multirow{2}{*}{$U_{3}$} & \multicolumn{2}{|c|}{ Period 1} & \multicolumn{2}{|c|}{ Period 2} & \multirow{2}{*}{$t$} & \multirow{2}{*}{$p(\%)$} \\
\hline & & & $h_{1}$ & $c_{1}$ & $h_{2}$ & $c_{2}$ & & \\
\hline \multirow{6}{*}{0.7} & 1.00 & 30.25 & 6.22 & 14.51 & 23.27 & 38.00 & 1.33 & 8.05 \\
\hline & 1.05 & 30.91 & 6.37 & 14.85 & 23.82 & 38.91 & 1.37 & 8.05 \\
\hline & 1.10 & 31.56 & 6.52 & 15.20 & 24.38 & 39.83 & 1.40 & 8.05 \\
\hline & 1.15 & 32.21 & 6.67 & 15.55 & 24.94 & 40.74 & 1.43 & 8.05 \\
\hline & 1.20 & 32.86 & 6.81 & 15.90 & 25.50 & 41.65 & 1.46 & 8.05 \\
\hline & 1.25 & 33.51 & 6.96 & 16.25 & 26.06 & 42.57 & 1.49 & 8.05 \\
\hline \multirow{6}{*}{1.0} & 1.00 & 29.01 & 11.25 & 26.25 & 11.25 & 26.25 & 0.00 & 0.00 \\
\hline & 1.05 & 29.63 & 11.52 & 26.88 & 11.52 & 26.88 & 0.00 & 0.00 \\
\hline & 1.10 & 30.26 & 11.79 & 27.51 & 11.79 & 27.51 & 0.00 & 0.00 \\
\hline & 1.15 & 30.88 & 12.06 & 28.14 & 12.06 & 28.14 & 0.00 & 0.00 \\
\hline & 1.20 & 31.51 & 12.33 & 28.77 & 12.33 & 28.78 & 0.00 & 0.00 \\
\hline & 1.25 & 32.13 & 12.60 & 29.40 & 12.60 & 29.41 & 0.00 & 0.00 \\
\hline \multirow{6}{*}{1.7} & 1.00 & 26.82 & 17.10 & 39.92 & 2.40 & 9.53 & 2.79 & 65.87 \\
\hline & 1.05 & 27.40 & 17.52 & 40.88 & 2.46 & 9.76 & 2.86 & 65.87 \\
\hline & 1.10 & 27.98 & 17.93 & 41.85 & 2.52 & 9.99 & 2.92 & 65.87 \\
\hline & 1.15 & 28.56 & 18.35 & 42.81 & 2.58 & 10.22 & 2.99 & 65.87 \\
\hline & 1.20 & 29.13 & 18.76 & 43.76 & 2.63 & 10.45 & 3.06 & 65.87 \\
\hline & 1.25 & 29.71 & 19.17 & 44.72 & 2.69 & 10.67 & 3.12 & 65.87 \\
\hline
\end{tabular}

As represented in Table 3, when the rent ratio remains unchanged, the tenants will increase housing services consumption in period 2, corroborated with an increase in the expected future 
household income. Additionally, when registering a fixed rent ratio, the share of acceptable maximum transaction costs to housing services consumption will be a constant percentage, regardless of the changes in the household income. If the rent ratio is 1.7 , with the income ratio varying from 1 to 1.25 , the proportion of maximum transaction costs is $65.87 \%$. This implies that the changes in income will contribute to the absolute value of maximum transaction costs, but not to its relative value. To put it differently, the barriers of transaction costs in the process of housing adjustment are only associated with the changes of housing rents.

Figure 4 illustrates the changes in the transaction costs and its barriers to housing adjustment. When the rent ratio is different from 1 , the acceptable maximum transaction costs will rise along with an increase in the household income. When the rent ratio is less than 1, the acceptable transaction costs will decline as income is increasing. Meanwhile, the slope of the transaction costs curve gradually decreases under the same income ratio, indicating that the increasing rent ratio may help slow down the changes of acceptable transaction costs. If the rent ratio is higher than 1 , the acceptable transaction costs will rise with a growth of the rent ratio, but the changes in the magnitude and slope are smaller than those when the rent ratio below 1.

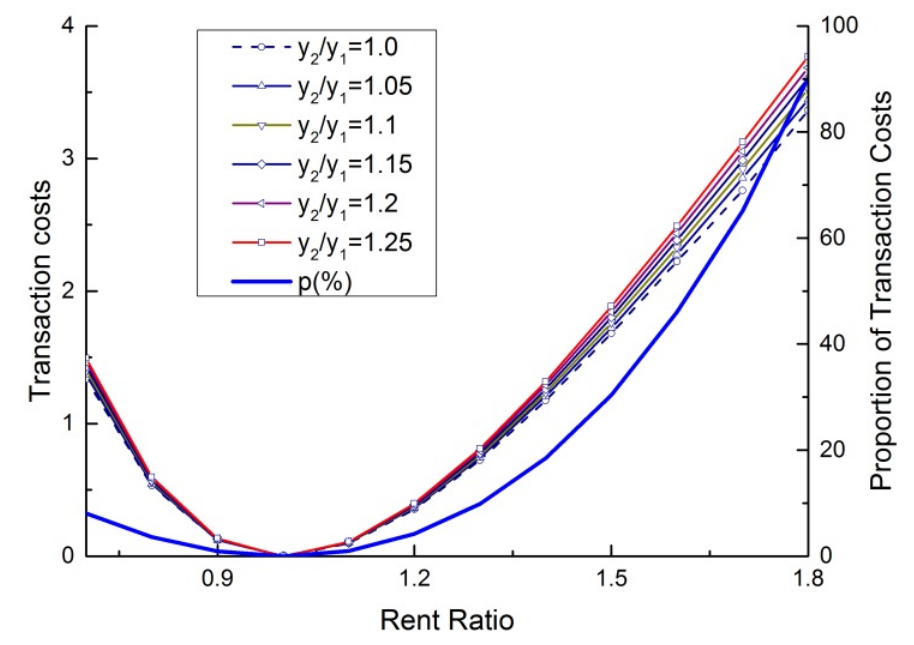

Figure 4. Transaction costs with changes in rent and income.

With respect to the barriers curve of transaction costs, the proportion of maximum acceptable transaction costs does not vary with the changes in the expected household income; the increase in income only raises the absolute value of transaction costs, not the relative one.

From the simulation results above, the housing rent in the private market has an inseparable impact on the rental transaction costs, which play a leading role in tenants' exit decisions and access to the private housing sector. Similarly, we also can calculate the range of tenants' acceptable rent ratio in both the private and public housing sector, with the changes of maximum transaction costs, as shown in Table 4.

Table 4. The range of housing rents under different transaction costs constraints.

\begin{tabular}{ccc}
\hline \multirow{2}{*}{$\boldsymbol{p ( \% )}$} & \multicolumn{2}{c}{$\boldsymbol{r}_{\mathbf{2}} / \boldsymbol{r}_{\mathbf{1}}$} \\
\cline { 2 - 3 } & Lower & Upper \\
\hline 8 & 0.701 & 1.267 \\
9 & 0.685 & 1.285 \\
10 & 0.669 & 1.301 \\
11 & 0.653 & 1.313 \\
12 & 0.637 & 1.325 \\
\hline
\end{tabular}


When the proportion of transaction costs to housing services consumption is going to be raised, the range of the rent ratio that tenants can afford will have the tendency to increase. This implies that if tenants can afford a higher proportion of transaction costs, they will also expand the scope in searching for housing in the private market.

It should be noted that the housing supply for low-income families is relatively small in the private market. It means that low-income households have to pay much higher search costs than high income families to find an affordable house. Although low-income tenants expect that their income will increase, they face high transaction costs due to the relatively tight supply in the private housing market. The range of housing rents they can afford will become narrower.

\section{Conclusions}

The main purpose of this paper was to simulate the impact of changes in tenants' household income and housing rents between the public and the private sector, and on tenants' total household utility. Furthermore, this paper also explored the main barriers of transaction costs with relation to the intention of exiting the PRH units. The paper's main finding is that housing rent in the private market may discourage tenants not eligible for the PRH units from searching for a suitable house in order to exit the public units, due to the barriers of transaction costs. In addition, our results indicate that when the rent ratio of the private to public rental housing is greater than 1 , the higher proportion of rental transaction costs to household consumption tends to create bigger barriers to PRH exits. Meanwhile, the tenants' acceptable maximum transaction costs will vary with the changes in the rent ratio after moving out of the PRH units. When the housing rent and tenants' income change at the same time, the acceptable maximum transaction costs also change, while the barriers are similar to those that arise with only changes in rent. The proportion of maximum acceptable transaction costs does not vary with the changes in the expected household income, though income growth only increases the absolute value of transaction costs, not the relative one. Consequently, if the maximum transaction costs or rents are more than tenants can afford, tenants might stop searching for another house and postpone the possibility of exiting, due to the constraints related to transaction costs. In this case, an alternative option for tenants is to continue to stay in the current PRH units.

The evidence simulated in this paper suggests that, for some tenants, the inability to exit may stem from barriers encountered while searching for a house in the private market. Household mobility necessarily involves a multitude of adjustments to other aspects of household behavior, and a household is unlikely to move immediately in response to changing needs or external stimuli [41]. A variety of solutions could be designed regarding the exit behavior of tenants to overcome such barriers, as increased exit rates will create vacancies for high-need applicants [42]. First, the local housing authority should set up a government-backed housing rental service and supervision platform, and provide information about available housing in the private market, to assist tenants who intend to leave as their leases run out. In addition, this assistance should expand tenants' housing choices, by expanding the potential suitable houses. Second, transaction costs are also important factors that discourage the intentions of some tenants to move out of the PRH units. The PRH landlords can motivate exits by providing moving subsidies and rent allowances for tenants turning to the private housing market. Third, housing supply characteristics can also play an indirect role in the low-income tenants' perceived problems, as they raise search costs and weaken the tenants' housing choices. Local governments should increase the land supplies to build more houses for rent, and provide all-round financial support for the construction of rental houses. Local governments should also combine the housing market with real estate destocking and encourage real estate developers to offer part of their housing inventory to rent rather than sale. These initiatives will expand the supply of affordable housing, and ensure that tenants are able to find decent housing, allowing them to integrate into the cities and local communities.

However, our simulations are subject to some limitations; thus, they are facing some biases because we have included only the barriers in the transaction costs to the PRH exits. The study by 
Barrett and Mosca [43] indicates that non-pecuniary elements, such as psychological costs like the emotional impact of leaving familiar neighborhood, also have an unfavorable influence on housing adjustment, suggesting that our simulations are insufficient with respect to the major barriers of transaction costs. Further research should investigate tenants' exit behaviors from both the subjective and objective barriers. Nevertheless, this task performed here is also essential, thus the findings from our research shed light on "exit difficulty" in the PRH sector.

Author Contributions: J.L. conceived and designed the research; J.L. collected data and analyzed the data; J.S. and X.N. contributed to progress of research idea; J.L., J.S., and X.X. wrote the paper. All authors have read and approved the final manuscript.

Acknowledgments: This research is supported by National Social Science Foundation of China (13BGL148).

Conflicts of Interest: The authors declare no conflict of interest.

\section{References}

1. Li, K. Implementing the massive-scale public housing program and improving housing policy and housing provision system step-by-step. Qiu Shi 2011, 53, 3-8. (In Chinese)

2. CPGC. The Goal of 36 Million Sets of Affordable Housing in 12th Five-Year Plan is Expected to Exceed the Target. Available online: http:/ / www.gov.cn/xinwen/2015-03/08/content_2830485.htm (accessed on 12 May 2016). (In Chinese)

3. Gao, B. Improving the mechanism of indemnificatory housing distribution and exit. Mod. Urban Res. 2012, 27, 29-31. (In Chinese)

4. NAOC. Real-Time Audit Results of Government-Subsidized Housing Projects in 2015 (General Serial No. 240). Available online: http://www.audit.gov.cn/en/n746/n752/n996/c96598/content.html (accessed on 12 December 2016).

5. Deng, H.Q.; Wang, Y.B. Research on the exit mechanism of rental housing based on evolutionary game theory. Guizhou Soc. Sci. 2015, 303, 123-127. (In Chinese)

6. MOHURD. Guidance on the Household Rental Subsidy for Secure Urban Housing. Available online: http:/ / www.mohurd.gov.cn/wjfb/201701/t20170110_230264.html (accessed on 28 February 2017).

7. Hooimeijer, P.; Oskamp, A. A simulation model of residential mobility and housing choice. J. Hous. Built. Environ. 1996, 11, 313-336. [CrossRef]

8. Peteke, F.; Maarten, V.H. Neighbourhood change ... reason to leave? Urban Stud. 2009, 46, 2103-2122.

9. Huang, Y.Q.; Deng, F.F. Residential mobility in Chinese cities: A longitudinal analysis. Hous. Stud. 2006, 21, 625-652. [CrossRef]

10. Fang, Y.H.; Zhang, R. Problems and resolution ways to the exit mechanism of China's indemnificatory housing. Urban Probl. 2013, 220, 79-83. (In Chinese)

11. Li, J.T.; Wang, C.C.; Sun, J. Empirical analysis of tenants' intention to exit public rental housing units based on the Theory of Planned Behavior-The case of Wuhan, China. Habitat Int. 2017, 69, 27-36. [CrossRef]

12. Pan, H.Y.; Zeng, Y.W.; Sun, Q.; Zhang, S.; Lin, J.W.; Zhang, X.M. Research on the tenants' willingness to vacate public rental housing and countermeasures: A case study of Chongqing. Constr. Econ. 2015, 36, 103-107. (In Chinese)

13. Rossi, P.H. Why Families Move: A Study in the Social Psychology of Urban Residential Mobility; Free Press: Glencoe, IL, USA, 1955.

14. Li, P.; Tu, Y. Behaviors on intra-urban residential mobility: A review and implications to future research. In IRES Working Paper Series; IRES2011-020; IRES: Singapore, 2011. Available online: http:/ / www.ires.nus. edu.sg/workingpapers/IRES2011-020.pdf (accessed on 19 May 2016).

15. Weisbrod, G.; Vidal, A. Housing search barriers for low-income renters. Urban Aff. Q. 1981, 16, 465-482. [CrossRef]

16. De Groot, C.; Mulder, C.H.; Manting, D. Intentions to move and actual moving behaviour in the netherlands. Hous. Stud. 2011, 26, 307-328. [CrossRef]

17. Lu, M. Analyzing migration decisionmaking: Relationships between residential satisfaction mobility intentions and moving behavior. Environ. Plan. A 1998, 30, 1473-1495. [CrossRef]

18. Baker, E.L. Public Housing Tenant Relocation: Residential Mobility, Satisfaction, and the Development of a Tenant's Spatial Decision Support System. Ph.D. Thesis, The University of Adelaide, Adelaide, Australia, 2002. 
19. Weinreb, L.; Rog, D.J.; Henderson, K.A. Exiting shelter: An epidemiological analysis of barriers and facilitators for families. Soc. Serv. Rev. 2010, 84, 597-614. [CrossRef] [PubMed]

20. Rosenblatt, P.; Deluca, S. “We don't live outside, we live in here": Neighborhood and residential mobility decisions among low-income families. City Community 2012, 11, 254-284. [CrossRef]

21. Kleit, R.G.; Galvez, M. The location choices of public housing residents displaced by redevelopment: Market constraints, personal preferences, or social information? J. Urban Aff. 2011, 33, 375-407. [CrossRef]

22. Kim, J.H.; Pagliara, F.; Preston, J. The intention to move and residential location choice behaviour. Urban Stud. 2005, 42, 1621-1636. [CrossRef]

23. Goodman, A.C. A dynamic equilibrium model of housing demand and mobility with transactions costs. J. Hous. Econ. 1995, 4, 307-327. [CrossRef]

24. Harmon, O.R.; Potepan, M.J. Housing adjustment costs: Their impact on mobility and housing demand elasticities. Real Estate Econ. 1988, 16, 459-478. [CrossRef]

25. Goodman, A.C. Modeling and computing transactions costs for purchasers of housing services. Real Estate Econ. 1990, 18, 1-21. [CrossRef]

26. Sánchez, A.C.; Andrews, D. To move or not to move: What drives residential mobility rates in the OECD. In OECD Economics Department Working Papers; No. 846; OECD Publishing: Paris, France, 2011.

27. Yang, Z.; Chen, J. Housing Affordability and Housing Policy in Urban China; Springer: Berlin, Germany, 2014.

28. Xie, N. Information Search and Invisible Transaction Cost in the Housing Market; Economic Science Press: Beijing, China, 2014. (In Chinese)

29. Zhang, H.; Zhang, X.G.; Lu, J.P.; Lin, Y.; Wang, M. Information Economics of Housing Market; Tsinghua University Press: Beijing, China, 2013. (In Chinese)

30. Zheng, S.Q. A Microeconomic Analysis of Housing Demand in China; China Architecture and Building Press: Beijing, China, 2007. (In Chinese)

31. Coley, R.L.; Kull, M.; Leventhal, T.; Lynch, A.D. Profiles of housing and neighborhood contexts among low-income families: Links with children's well-being. Cityscape 2014, 16, 41-64.

32. Linneman, P.; Wachter, S.M. The impacts of borrowing constraints on homeownership. Real Estate Econ. 1989, 17, 389-402. [CrossRef]

33. Kleit, R.G.; Kang, S.; Scally, C.P. Why do housing mobility programs fail in moving households to better neighborhoods. Hous. Policy Debate 2016, 26, 188-209. [CrossRef]

34. Ritsila, J.; Ovaskainen, M. Migration and regional centralization of human capital. Appl. Econ. 2001, 33, 317-325. [CrossRef]

35. Morrison, P.S.; Clark, W.A.V. Why do they stay? Loss aversion and duration of residence. In California Center for Population Research On-Line Working Paper Series; CCPR: Los Angeles, CA, USA, 2015.

36. Nepal, B.; Tanton, R.; Harding, A. Measuring housing stress: How much do definitions matter? Urban Policy Res. 2010, 28, 211-224. [CrossRef]

37. Kahneman, D. Thinking, Fast and Slow; Farrar Straus and Giroux: New York, NY, USA, 2011.

38. Engelhardt, G.V. Nominal loss aversion, housing equity constraints, and household mobility: Evidence from the United States. J. Urban Econ. 2003, 53, 171-195. [CrossRef]

39. Bartik, T.J.; Butler, J.S.; Liu, J. Maximum score estimates of the determinants of residential mobility: Implications for the value of residential attachment and neighborhood amenities. J. Urban Econ. 1992, 32, 233-256. [CrossRef]

40. Quigley, J.M. Transactions costs and housing markets. In Berkeley Program on Housing and Urban Policy, Working Paper Series; No. W02-005; University of California: Berkeley, CA, USA, 2002.

41. Kan, K. Expected and unexpected residential mobility. J. Urban Econ. 1999, 45, 72-96. [CrossRef]

42. Wiesel, I.; Pawson, H. Why do tenants leave social housing? Exploring residential and social mobility at the lowest rungs of Australia's socioeconomic ladder. Aust. J. Soc. Issues 2015, 50, 397-417. [CrossRef]

43. Barrett, A.; Mosca, I. The psychic costs of migration: Evidence from Irish return migrants. J. Popul. Econ. 2013, 26, 483-506. [CrossRef]

(C) 2018 by the authors. Licensee MDPI, Basel, Switzerland. This article is an open access article distributed under the terms and conditions of the Creative Commons Attribution (CC BY) license (http:/ / creativecommons.org/licenses/by/4.0/). 